\title{
POTENSI AIRTANAH BEBAS PADA AKUIFER TIDAK TERTEKAN PADA SEBAGIAN WILAYAH DUSUN GROGOL VII, VIII, DAN IX, PARANGTRITIS, KRETEK, BANTUL
}

\author{
Muhammad Ridho Irshabdillah1 \\ 1Departemen Geografi Lingkungan Fakultas Geografi Universitas Gadjah Mada \\ Email: ${ }^{1}$ m.ridho.irshabdillah@mail.ugm.ac.id
}

\begin{abstract}
INTISARI
Airtanah mempunyai peranan penting dalam kehidupan manusia. Akan tetapi potensi airtanah di setiap daerah tidak selalu sama. Beberapa daerah dapat ditemukan airtanah yang melimpah dan beberapa daerah lain sulit ditemukan airtanah. Tujuan penelitian ini adalah untuk mengevaluasi potensi airtanah bebas yang terbatas pada akuifer tidak tertekan di sebagian Dusun Grogol VI, VIII, dan IX. Terdapat dua satuan litologi utama wilayah kajian yaitu satuan aluvial (Qa) yang menempati sebagian besar wilayah Dusun Grogol, terutama di Grogol bawah (Grogol VII, VIII, dan IX) dan Formasi Nglanggeran (Tmn) yang menempati wilayah Grogol atas (Grogol VII dan VIII). Penelitian dilakukan dengan membuat flownets, uji pompa, dan mengukur data kualitas airtanah. Hasil penelitian menunjukkan bahwa airtanah pada wilayah kajian melimpah. Rata-rata airtanah dapat ditemukan pada kedalaman 1 hingga 3 meter. Ketika musim kemarau tidak terjadi kekeringan yang berarti pada sumur penduduk. Sumber airnya berasal dari recharge area yang berada di lereng Perbukitan Baturagung yang berada di sebelah timur wilayah kajian. Aliran airtanah bergerak ke selatan dan barat menuju dataran alluvial yang berada di bawahnya. Hasil perhitungan debit berdasarkan parameter-parameter yang didapatkan dari uji pompa metode slug test sebesar 1.235,5 m³/hari. Berdasarkan uji kualitas air, sebagian besar air pada sumur-sumur warga tergolong pada kondisi aman untuk dikonsumsi.
\end{abstract}

Kata Kunci : Airtanah, Potensi Airtanah, Flownet, Debit, Kualitas Air

\section{PENDAHULUAN}

Peran airtanah semakin lama semakin penting dan strategis karena menyangkut kebutuhan pokok hajat hidup orang banyak dalam berbagai aktivitas hidupnya. Supaya pemanfaatan airtanah dapat dilakukan secara berkelanjutan, dalam penggunaannya harus memperhatikan potensi ketersediaan dan perubahan-perubahan yang terjadi akibat pemanfaatannya tidak menimbulkan dampak negatif yang berarti baik bagi airtanah maupun lingkungan di sekitarnya. Oleh karena itu, diperlukan evaluasi potensi airtanah sebagai dasar perencanaan konservasi dan pendayagunaannya.

Data mengenai potensi/ketersediaan airtanah sangat penting untuk diketahui agar dapat mengetahui persediaan air yang dapat menyuplai kebutuhan masyarakat di sebagian Dusun Grogol VII, VIII, dan IX. Setap wilayah memiliki karakteristik yang berbeda sehingga potensi airtanahnya berbeda pula. Potensi/ketersediaan air juga untuk melihat apakah di suatu wilayah kajian merupakan wilayah yang kekeringan akan air atau wilayah yang melimpah volume airnya, mengamati aliran air yang terjadi, serta menganalisa apakah terjadi penggunaan air berlebihan pada wilayah tertentu. 
Data potensi airtanah di Dusun Grogol akan memberikan manfaat dalam penggunaan atau pemanfaatan airtanah yakni, banyak air maksimal yang dapat diambil sehingga ketersediaan air tetap tercukupi. Informasi potensi airtanah di Dusun Grogol penting karena airtanah merupakan sumber air yang memiliki kuantitas maupun kualitas yang lebih baik. Selain itu data ini akan menjadi sumber perencanaan baik bagi pemerintah setempat maupun masyarakat untuk mengetahui seberapa besar potensi airtanah di wilayahnya. Ketika diketahui potensi airtanahnya rendah, maka akan diketahui solusi untuk mengatasi masalah tersebut, seperti dengan pemanfaatan potensi mata air di sekitarnya. Sehingga dapat direncanakan langkah lebih lanjut untuk mengatasi masalah tersebut, jadi data potensi airtanah akan bermanfaat untuk penentuan letak sumber airtanah yang melimpah.

\section{ISI}

Potensi airtanah pada setap daerah sangat dipengaruhi oleh berbagai faktor, antara lain kondisi geologi, kondisi hidrologi, dan vegetasi penutup (Sudarmadji dkk, 2014). Kondisi relief wilayah kajian, secara umum terdiri atas daerah berbukit dan daerah berbukit. Berdasarkan tinjauan litologi daerah kajian, menurut Bemmelen (1970) litologi utama di wilayah Dusun Grogol VII, VIII, dan IX terdiri atas dua bagian, yaitu alluvium (Qa) dan Formasi Ngalnggeran (Tmn). Satuan aluvium (Qa) terdiri atas kerakal, pasir, lempung, dan lanau. Formasi Nglanggeran terdiri atas breksi vulkanik, breksi aliran, alglomerat, lava, dan tuff. Kondisi relief dan litologi utama berpengaruh terhadap kondisi aliran airtanah apakah termasuk dalam sistem isotropis ataukah anisotropis, tergantung kepada porositas batuan yang mengkontrolnya. Sistem isotropis meupakan sistem dimana aliran airtanah memiliki kesempatan yang sama untuk mengalir ke segala arah, sementara sistem anisotropis merupakan sistem dimana kondisi aliran airtanah tidaklah sama pada setiap arahnya. Sistem isotropis menempati daerah yang berelief datar dengan material lepas-lepas seperti pasiran, kerakal, dan sebagainya. Sistem anisotropis menempat daerah dengan relief berbukit dengan material kompak. Oleh karena itu, sistem aliran airtanah yang bisa dibuat jaring aliran airtanah (flownet) adalah sistem isotropis (gambar 1).

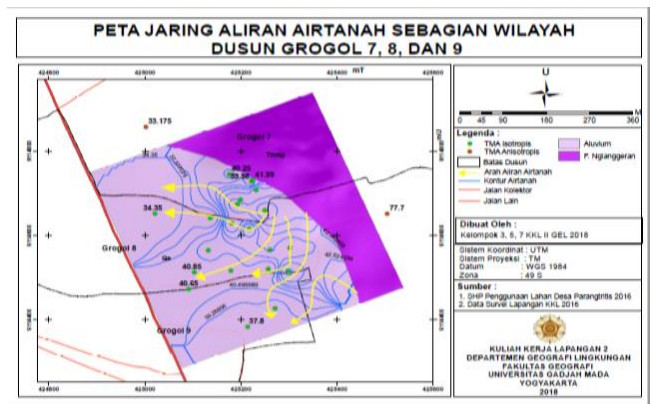

Gambar 1 Peta Geologi Sebagian Dusun Grogol 7, 8, dan 9 
Karakteristik fisik airtanah yang akan dianalisis meliput kedalaman muka airtanah dan kondisi fisik airtanah di lapangan (rasa, bau, dan warna). Pengukuran kedalaman muka airtanah dilakukan pada 23 sampel sumur gali. Kondisi fisik airtanah saat dilakukan pengukurn pada setiap sampel sumur memiliki kondisi yang cukup baik, seperti warna yang benik, tidak berbau, dan tidak berasa. Berdasarkan data dari tabel 1 menunjukkan bahwa variasi kedalaman muka airtanah yang telah dihitung berkisar antara 1-3,8 $\mathrm{m}$ dengan tinggi muka airtanah antara 33-46 mdpl. Ketinggian muka airtanah mengikut kondisi topografi, dimana semakin tinggi elevasi suatu daerah, maka semakin tinggi pula tinggi muka airtanahnya dan semakin tinggi pula tekanannya. Informasi tinggi muka airtanah dari setap sampel sumur yang diukur kemudian diinterpolasi sehingga membentuk kontur muka airtanah. Garis kontur muka airtanah sering disebut sebagai garis equipotensial. Berdasarkan informasi tersebut, maka garis aliran airtanah dapat diketahui dengan membuat garis tegak lurus dengan garis equipitensial. Grais equipotensial dan garis aliran yang digambarkan dalam peta disebut sebagai jaring aliran airtanah (flownet).

Berdasarkan peta jarring kontur aliran airtanah yang dibuat maka dapat diketahui daerah imbuhan (recharge) dan daerah penurapan (discharge) pada suatu wilayah. Kontur cembung menunjukan sebuah recharge area, sedangkan kontur cekung menunjukan discharge area (Purnama, 2010). Oleh karena itu, terjadi aliran airtanah dari daerah yang bertekanan tinggi menuju daerah yang bertekanan rendah. Wilayah kajian merupakan discharge area yang mendapatkan supply dari recharge area. Recharge area dalam kajian ini meliput perbukitan Baturagung yang berada di sebelah timur wilayah kajian. Air di recharge area ini mengalir ke wilayah yang lebih rendah hingga akhirnya memasok airtanah di wilayah kajian. Sebagian besar airtanah di wilayah kajian bergerak ke selatan dan barat menuju daerah dataran di bawahnya.

Tabel 1 Tabel Hasil Pengukuran Tinggi Muka Airtanah

\begin{tabular}{|c|c|c|c|c|c|c|}
\hline $\begin{array}{c}\text { No. } \\
\text { Sumur }\end{array}$ & $\mathrm{X}$ & $\mathrm{Y}$ & $\mathrm{Z}$ & $\begin{array}{c}\text { TMA } \\
(\mathrm{m})\end{array}$ & $\begin{array}{c}\text { TMA } \\
(\mathrm{mdpl})\end{array}$ & $\begin{array}{c}\text { Beda } \\
\text { Tinggi }\end{array}$ \\
\hline $1 \mathrm{a}$ & 425504.615 & 9114650.83 & 77.8 & 0.1 & 77.7 & \\
\hline $2 \mathrm{a}$ & 425298.899 & 9114513.598 & 45.4 & 1.92 & 43.48 & -32.4 \\
\hline $3 \mathrm{a}$ & 425301.693 & 9114570.101 & 44.4 & 2.74 & 41.66 & 1 \\
\hline $4 \mathrm{a}$ & 425260.866 & 9114565.352 & 44.4 & 2.33 & 42.07 & 0 \\
\hline a & 425217 & 9114615 & 43.8 & 2.62 & 41.18 & -0.6 \\
\hline a & 425132 & 9114565 & 42.8 & 1.14 & 41.66 & -1 \\
\hline $7 \mathrm{a}$ & 425103 & 9114513 & 41.6 & 0.75 & 40.85 & -1.2 \\
\hline $8 \mathrm{a}$ & 425091 & 9114472 & 41.6 & 0.95 & 40.65 & 0 \\
\hline $9 \mathrm{a}$ & 425179 & 9114516 & 41.8 & 0.88 & 40.92 & 0.2 \\
\hline $10 \mathrm{a}$ & 425257 & 9114520 & 41.6 & 1.12 & 40.48 & -0.2 \\
\hline $11 \mathrm{a}$ & 425271 & 9114427 & 39.4 & 0.52 & 38.88 & -2.2 \\
\hline $12 \mathrm{a}$ & 425214 & 9114383 & 39 & 1.2 & 37.8 & -0.4 \\
\hline $1 \mathrm{~b}$ & 425222 & 9114728 & 43 & 3.02 & 39.98 & -34.8 \\
\hline $2 \mathrm{~b}$ & 425225 & 9114731 & 46.4 & 4.41 & 41.99 & 3.4 \\
\hline $3 \mathrm{~b}$ & 425232 & 9114707 & 47 & 4.02 & 42.98 & 0.6 \\
\hline $4 \mathrm{~b}$ & 425199 & 9114685 & 46.2 & 3.71 & 42.49 & -0.8 \\
\hline 5b & 425176 & 9114745 & 43.6 & 3.35 & 40.25 & -2.6 \\
\hline 6b & 425250 & 9114659 & 49.6 & 3.195 & 46.405 & 6 \\
\hline $7 \mathrm{~b}$ & 425193 & 9114674 & 48.2 & 3.38 & 44.82 & -1.4 \\
\hline $8 \mathrm{~b}$ & 425181 & 9114628 & 46.8 & 3.38 & 43.42 & -1.4 \\
\hline $9 \mathrm{~b}$ & 425136 & 9114641 & 40.2 & 3.07 & 37.13 & -6.6 \\
\hline $10 \mathrm{~b}$ & 425021 & 9114651 & 37 & 2.65 & 34.35 & -3.2 \\
\hline $11 \mathrm{~b}$ & 425002 & 9114857 & 37 & 3.825 & 33.175 & 0 \\
\hline
\end{tabular}


Aliran airtanah mayoritas mengarah ke selatan dan barat, sehingga dapat dimungkinkan bahwa airtanah banyak terakumulasi di dusun Grogol VIII dan Grogol IX. Pola permukiman penduduk yang mengelompok di dataran rendah di bawah Perbukitan Baturagung juga mengindikasikan ketersediaan airtanah yang melimpah di daerah tersebut (gambar 2). Berdasarkan penuturan dari warga lokal, hampir semua sumur tidak pernah mengalami kekeringan yang berart. Walaupun saat musim kemarau tinggi muka airtanah turun, tetapi kedalaman keturunan tidak melebihi 2-3 meter dari tinggi muka airtanah mulamula. Hal ini menunjukkan bahwa wilayah kajian memiliki jumlah airtanah yang melimpah.

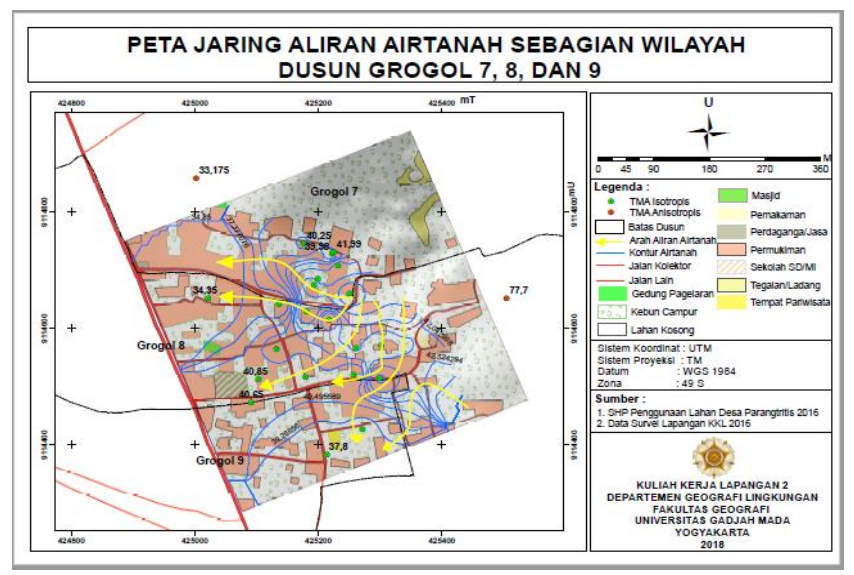

Gambar 2 Peta Penggunaan Lahan Sebagian Dusun Grogol 7, 8, dan 9

Pumping test merupakan metode terbaik untuk mengetahui konduktivitas hidrolik dilapangan (Purnama, 2010). Pumping dengan metode slug test dianggap sebagai teknik cepat dan murah untuk menentukan konduktivitas hidrolik (Fabbri, 2012). Konduktivitas hidraulik merupakan salah satu parameter akuifer yang menentukan keberlanjutan air bawah tanah di suatu daerah (Hutasoit, 2009). Nilai konduktivitas hidraulik suatu akuifer tergantung pada material penyusun akuifer tersebut. Hasil perhitungan dari uji pompa pada sumur pertama menunjukkan nilai $\mathrm{K}$ yaitu $4,755 \mathrm{~m} / \mathrm{hari}$. Hasil tersebut menunjukkan klasifkasi nilai $\mathrm{K}$ untuk berbagai jenis tanah atau batuan menurut Todd (1980) masuk ke dalam sandstone, medium grained atau batu pasir berbutir sedang. Nilai transmisivitas diperoleh sebesar 18,02 $\mathrm{m}^{2} /$ hari. Hasil perhitungan uji pompa pada sumur kedua diperoleh nilai konduktivitas hidraulik sebesar 0,47 m/hari yang menurut Todd (1980) nilai tersebut masuk dalam klasifkasi predominantly sand atau didominasi oleh pasir dengan nilai transmisivitas sebesar 1,71 $\mathrm{m}^{2} / \mathrm{hari}$.

Nilai konduktivitas hidrolik dapat digunakan untuk menghitung debit airtanah pada akuifer. Debit merupakan volume air yang mengalir persatuan waktu (Neno dkk., 2016). Debit airtanah dapat dihitung melalui jaring-jaring aliran dengan Metode Darcy. Perhitungan 
debit Metode Darcy mempertimbangkan konduktivitas hidrolik, kemiringan aliran airtanah, dan luas penampang akuifer. Perhitungan debit di lokasi kajian menggunakan nilai konduktivitas hidrolik hasil dari pumping test. Nilai dari konduktivitas hidrolik tersebut sebesar $4,755 \mathrm{~m} / \mathrm{hari}$, sedangkan gradien hidroliknya $1,498 \times 10^{-3}$. Hasil perhitungan debit berdasarkan parameter-parameter yang sudah diketahui sebesar $1.235,5 \mathrm{~m}^{3} / \mathrm{hari}$. Hasil sensus dari data social ekonomi KKL 2 GEL 2018 mengenai konsumsi air per rumah tangga sebesar 144,353 $\mathrm{m} 3 /$ hari, sehingga dapat diasumsikan bahwa dengan debit 1.235,5 m3/hari cukup untuk memenuhi kebutuhan warga setiap harinya. Oleh karena itu di Dusun Grogol airtanah menjadi sumber utama dalam memenuhi kebutuhan air masyarakat.

Selain menggunakan sumur sebagai seumber penyedia kebutuhan akan air, sebagian masyarakat Dusun Grogol, terutama Grogol bagian atas juga memanfaatkan keberadaan maatair sebagai sumber pemenuhan kebutuhan air mereka. Sebagian masyarakat yang memanfaatkan mataair tersebut merupakan masyarakat yang tinggal di lereng kaki dan lereng bawah Perbukitan Baturagung yang merupakan daerah anisotropis. Mataair yang dapat dijumpai di Perbukitan Baturagung dapat berupa mataair tekuk lereng (depression spring), mataair kontak (contact spring), dan rembesan (seepage). Mataair tekuk lereng merupakan mataair yang terbentuk akibat terpotongnya muka airtanah oleh permukaan tanah. Mataair ontak merupakan mataair yang muncul pada daerah pertemuan antara batuan kedap air dan lolos air. Rembesan adalah mataair yang menyebar sangat luas dan keluar secara perlahan-lahan (Purnama, 2010). Mataair kontak yang muncul di Perbukitan Baturagung dipengaruhi oleh adanya struktur dan aktivitas vulkanik masa tersier dan juga karena adanya kontak antara batuan gamping dan nongamping pada bagian atas (Santosa, 2014). Debit yang keluar dari mataair di Perbukitan Baturagung cenderung dan bersifat intermittent.

Kualitas air merupakan salah satu parameter penting untuk diukur, utamanya untuk mengetahui kelayakan air untuk dikonsumsi. Kondisi kualitas air pada suatu daerah dipengaruhi oleh faktor-faktor tertentu, yaitu iklim, batuan, topografi, waktu, dan manusia (Santosa dan Adji, 2014). Empat faktor awal dikenal sebagai faktor alami sedangkan faktor manusia merupakan faktor nonalami. Pada perkembangan selanjutnya faktor manusia menjadi faktor yang paling dominan mempengaruhi kondisi kualitas air, dimana pada akhirnya terjadi degradasi lingkungan yang imbasnya juga mempengaruhi kebutuhan domestic, termasuk pemenuhan kebutuhan akan air bersih. Keempat faktor lainnya cenderung bersifat stabil dan mempengaruhi kondisi kimia airtanah dalam jangka waktu yang lama.

Parameter yang diukur dalam uji kualitas airtanah di Dusun Grogol yaitu pH, DHL, suhu, salinitas, dan TDS (tabel 2). Keempat parameter tersebut diukur menggunakan water quality checker. Derajat keasaman $(\mathrm{pH})$ dipengaruhi oleh kondisi geologi dan batuan suatu daerah. Nilai $\mathrm{pH}$ mempengaruhi proses kimiawi perairan seperti nitrifikasi. Airtanah layak 
dikonsumsi apabila memiliki $\mathrm{pH}$ netral, tidak asam maupun tidak basa. Airtanah di Dusun Grogol 7, 8, dan 9 berkisar antara 5,65-7, 52. Nilai pH air normal berkisar 6,5-7,5, dimana ph $<6,5$ maka air bersifat asam dan $\mathrm{pH}>7,5$ maka air bersifat basa. Berdasarkan data $\mathrm{pH}$ yang diambil pada titk sampel yang menyebar di Dusun Grogol 7, 8, dan 9 sebanyak 13 sumur sampel memiliki kadar $\mathrm{pH}$ normal, dan sisanya memiliki $\mathrm{pH}$ asam. Airtanah dengan $\mathrm{pH}$ asam lebih banyak dibanding dengan $\mathrm{pH}$ air sedikit basa. Airtanah dengan $\mathrm{pH}$ asam ini kemungkinan disebabkan adanya kontaminasi limbah dalam sumur, baik berupa limbah domestik maupun limbah peternakan.

Tabel 2 Data Kualitas Air Dusun Grogol

\begin{tabular}{|c|c|c|c|c|c|c|c|}
\hline $\begin{array}{c}\text { No. } \\
\text { Sumur }\end{array}$ & $\mathrm{x}$ & $\mathrm{Y}$ & $\mathrm{pH}$ & $\begin{array}{c}\mathrm{DHL} \\
(\text { umhos } / \mathrm{cm})\end{array}$ & Salinitas & Suhu $\left({ }^{\circ} \mathrm{C}\right)$ & \begin{tabular}{|c} 
TDS \\
$(\mathrm{mg} /$ Liter $)$
\end{tabular} \\
\hline 1a & 425504.615 & 9114650.83 & 6.09 & 746 & 360 & 28.3 & 529 \\
\hline $2 \mathrm{a}$ & 425298.899 & 9114513.598 & 7.08 & 451 & 271 & 27.8 & 320 \\
\hline $3 a$ & 425301.693 & 9114570.101 & 6.95 & 855 & 525 & 28.1 & 608 \\
\hline $4 a$ & 425260.866 & 9114565.352 & 6.8 & 672 & 410 & 27.8 & 478 \\
\hline $5 a$ & 425217 & 9114615 & 7.36 & 454 & 275 & 26.9 & 322 \\
\hline $6 \mathrm{a}$ & 425132 & 9114565 & 6.81 & 730 & 446 & 29.1 & 518 \\
\hline $7 \mathrm{a}$ & 425103 & 9114513 & 7.52 & 640 & 390 & 30.6 & 458 \\
\hline $8 a$ & 425091 & 9114472 & 7.03 & 750 & 447 & 28.5 & 578 \\
\hline $9 \mathrm{a}$ & 425179 & 9114516 & 6.9 & 705 & 430 & 29.6 & 503 \\
\hline $10 \mathrm{a}$ & 425257 & 9114520 & 7.33 & 442 & 265 & 27.8 & 311 \\
\hline 11a & 425271 & 9114427 & 7.11 & 751 & 452 & 28 & 530 \\
\hline $12 \mathrm{a}$ & 425214 & 9114383 & 6.9 & 663 & 387 & 28.4 & 452 \\
\hline $1 \mathrm{~b}$ & 425222 & 9114728 & 5.65 & 533 & 258 & 28.4 & - \\
\hline $2 \mathrm{~b}$ & 425225 & 9114731 & 5.9 & 766 & 367 & 28.3 & . \\
\hline $4 \mathrm{~b}$ & 425199 & 9114685 & 5.8 & 535 & 406 & 28.5 & - \\
\hline $5 \mathrm{~b}$ & 425176 & 9114745 & 5.78 & 888 & 435 & 28.4 & - \\
\hline $6 \mathrm{~b}$ & 425250 & 9114659 & 5.9 & 472 & 221 & 28 & - \\
\hline $8 b$ & 425181 & 9114628 & 6.44 & 483 & 233 & 27.8 & - \\
\hline $9 \mathrm{~b}$ & 425136 & 9114641 & 5.82 & 461 & 222 & 27.3 & - \\
\hline $10 \mathrm{~b}$ & 425021 & 9114651 & 5.87 & 704 & 338 & 28.2 & - \\
\hline $11 \mathrm{~b}$ & 425002 & 9114857 & 5.86 & 662 & 332 & 28.5 & - \\
\hline
\end{tabular}

Daya Hantar Listrik turut mempengaruhi kualitas air pada mataair. Airtanah pada sumur sampel yang diukur memiliki nilai Daya Hantar Listrik (DHL) yang berkisar antara 442 $\mu \mathrm{mhos} / \mathrm{cm}$ hingga $850 \mu \mathrm{mhos} / \mathrm{cm}$. Aitanah pada sumur sampel berdasarkan nilai daya hantar listriknya termasuk dalam kondisi perairan normal. Perairan normal memiliki nilai DHL berkisar antara 20 - $1500 \mu \mathrm{S} / \mathrm{cm}$ (Boyd, 1982). Mayoritas air sumur di Dusun Grogol layak dikonsumsi. Hal tersebut dikarenakan mataair-mataair tersebut memenuhi nilai DHL yang berada dalam ambang batas air layak minum. Air layak minum memiliki nilai DHL dalam ambang batas antara $20 \mu \mathrm{S} / \mathrm{cm}$ hingga $12500 \mu \mathrm{S} / \mathrm{cm}$ (Mukarromah, 2016). Semakin kecil nilai DHL maka semakin baik kualitas air pada sumur sampel dan sebaliknya, semakin besar nilai DHL semakin buruk kualitas air pada sumur sampel.

TDS (Total Dissolve Solid) merupakan nilai yang menunjukkan total padatan yang terlaurut dalam suatu larutan. TDS merupakan indikator dari jumlah partikel atau zat tersebut, baik berupa senyawa organik maupun non-organik. Zat atau partikel padat terlarut yang ditemukan dalam air dapat berupa natrium (garam), kalsium, magnesium, kalium, karbonat, nitrat, bikarbonat, klorida dan sulfat. Nilai TDS di Dusun Grogol berkisar antara 311 mg/L-608 mg/L. Berdasarkan PERMENKES 907/Menkes/SK/VII/2002 standar TDS aman untuk berkisar antara $500 \mathrm{mg} / \mathrm{L}-1000 \mathrm{mg} / \mathrm{L}$, sehingga airtanah di Dusun Grogol layak untuk dikonsumsi. Semakin tingginya nilai TDS menunjukkan semakin tinggi tingkat kesadahan air (Mulia, 2005). Kemungkinan senyawa yang terlarut dalam air sumur yaitu senyawa karbonat. 
Hal tersebut dibuktikan dengan ditemukannya kerak-kerak puth pada ember yang digunakan untuk menimba air sumur tersebut.

Salinitas yang terukur pada tap sumur sampel berkisar antara 221-525 ppm. Nilai salinitas yang rendah menunjukkan bahwa akuifer di Dusun Grogol tidak dipengaruhi oleh aktivitas-aktivitas marine. Temperatur air sumur pada sumur sampel berkisar antara $26,9^{\circ} \mathrm{C}$ - 30,6 $6^{\circ} \mathrm{C}$. Pengukuran temperatur dilakukan secara langsung pada tap mataair pada pukul 09.00 hingga sekitar pukul 16.00 WIB. Besar temperatur juga dipengaruhi oleh keberadaan tanaman akuatik dan vegetasi di sekitar area sumur sampel.

\section{PENUTUP/KESIMPULAN}

Kajian hidrologi yang dilakukan di Dusun Grogol VII,VIII, dan IX menunjukkan bahwa aliran airtanah mayoritas mengarah ke selatan dan barat, ketersediaan airtanah juga melimpah dengan $\mathrm{pH}$ berkisar antara 5,65 - 7, 52. Nilai Daya Hantar Listrik (DHL) berkisar antara $442 \mu \mathrm{mhos} / \mathrm{cm}$ hingga $850 \mu \mathrm{mhos} / \mathrm{cm}$ (normal). Nilai TDS di Dusun Grogol berkisar antara $311 \mathrm{mg} / \mathrm{L}-608 \mathrm{mg} / \mathrm{L}$ (layak dikonsumsi). Salinitas yang terukur pada tiap sumur sampel berkisar antara 221-525 ppm. Nilai salinitas yang rendah menunjukkan bahwa akuifer di Dusun Grogol tidak dipengaruhi oleh aktivitas-aktivitas marine. Temperatur air sumur pada sumur sampel berkisar antara $26,9^{\circ} \mathrm{C}-30,6^{\circ} \mathrm{C}$. Akuifer pada wilayah pumping test 1, mampu meloloskan airtanah sebesar 4,755 m/hari tergolong material sandstone, medium grained atau batu pasir berbutir sedang, dengan nilai transmisivitas sebesar 18,02 $\mathrm{m}^{2} /$ hari. Sementara pumping test-2 diperoleh nilai konduktivitas hidraulik sebesar $0,47 \mathrm{~m} /$ hari dengan material predominantly sand atau didominasi oleh pasir dengan nilai transmisivitas sebesar 1,71 $\mathrm{m}^{2} /$ hari. Hasil perhitungan debit berdasarkan parameter-parameter yang sudah diketahui sebesar $1.235,5 \mathrm{~m}^{3} /$ hari, sedangkan konsumsi air per rumah tangga sebesar $144,353 \mathrm{~m}^{3} /$ hari, sehingga dapat diasumsikan bahwa dengan debit $1.235,5 \mathrm{~m}^{3} /$ hari cukup untuk memenuhi kebutuhan warga setiap harinya. Oleh karena itu di Dusun Grogol airtanah menjadi sumber utama dalam memenuhi kebutuhan air masyarakat.

\section{UCAPAN TERIMA KASIH}

Ucapan terima kasih penulis sampaikan kepada rekan-rekan GEL 2016 pada umumnya, wabil khusus kepada rekan-rekan kelompok 7 Desa Grogol atas kerja samanya yang kompak saat pengambilan data hidrologi berlangsung serta suasana kekeluargaan yang telah diberikan selama ini. Terima kasih juga penulis haturkan kepada asisten praktikum hari Rabu pukul 13.00, mas Fuad dan mbak Nindha atas ilmu serta bimbingannya selama praktikum geohidrologi berlangsung. 


\section{DAFTAR PUSTAKA}

Boyd, C. E. 1988. Water Quality in Warmwater Fish Ponds. Alabama: Auburn University Agricultural Experient Station.

Fabbri, P., Ortombina, M., dan Piccinini, L.. 2012. Estimation of Hydraulic Conductivity Using the Slug Test Method in a Shallow Aquifer in the Venetian Plain (NE, Italy). AQUA mundi, Vol.4. Hal: $125-133$.

Hutasoit, L.M. 2009. Kondisi Permukaan Air Tanah dengan dan Tanpa Peresapan Buatan di daerah Bandung. Jurnal Geologi Indonesia. Vol.14. Hal: 177-188.

Mukarromah, R. 2016. Analisis Sifat Fisis Dalam Studi Kualitas Air di Mata Air Sumber Asem Dusun Kalijeruk, Desa Siwuran, Kecamatan Garung, Kabupaten Wonosobo. Laporan Penelitian. Universitas Negeri Semarang.

Mulia, R. M. 2005. Pengantar Kesehatan Lingkungan. Yogyakarta: Penerbit Graha Ilmu.

Neno, A.K., Harijanto, H., dan Wahid, A. 2016. Hubungan Debit Air dan Tinggi Muka Air di Sungai Lambagu Kecamatan Tawaeli Kota Palu. Warta Rimba Vol 6. Hal: 12-23.

Purnama, S. 2010. Hidrologi Air Tanah. Yogyakarta: Penerbit Kanisius.

Santosa, L. W, dan Tjahyo N. A. 2014. Karakteristik Akuifer dan Potensi Airtanah Graben Bantul. Yogyakarta: Gadjah Mada Unibersity Press.

Sudarmadji, Pramonohadi, dan M. Widyastuti. 2014. Pengelolaan Sumberdaya Air Terpadu. Yogyakarta: Gadjah Mada University Press.

Todd, D. K. 1980. Groundwater Hydrology. New York: John Wiley and Sons. 